\title{
Religió i religiositat en el Tirant lo Blanc
}

\author{
Religion and religiosity in Tirant lo Blanc
}

\author{
ANTON M. EsPADALER \\ anton.espadaler@gmail.com
}

Universitat de Barcelona

Resum: El treball posa en relleu dues maneres de desenvolupar els aspectes religiosos en el Tirant lo Blanc. Una manera que encaixa amb dificultat amb la doctrina de l'Església, però que sembla ajustars'hi quan la pràctica de la cavalleria pren forma de croada, mentre s'exposa una vivència formal, externa i rutinària del cristianisme, malgrat la seva omnipresència; i una altra en què hom procura respectar els articles de la fe i reconduir les conductes dels personatges a una experiència de la fe menys acomodatícia, i més preocupada per les exigències doctrinals.

Paraules clau: Religió, Martorell, Tirant, croada, cavalleria, erotisme, humor, psalms, litúrgia.

\begin{abstract}
This paper highlights two ways of explaining the religious matter in the Tirant lo Blanc. One way that hardly agrees with the Church's doctrine, but seems to do so when the practice of chivalry takes form of crusade, meanwhile extending a formal, external and routine experience of Christianity, in spite of its omnipresence; and another one in which the writer tries to respect the articles of Faith and to redirect the behavior of the characters into a less accommodative faith experience, and more concerned with doctrinal requirements.
\end{abstract}

Keywords: Religion, Martorell, Tirant, crusade, chivalry, erotism, humour, psalms, liturgy. 
Encara que els gestos de la pietat no siguin tots els mateixos que en el segle XV -són molt pocs, si és que són, els qui adopten l'actitud d'orants, com el marquès de Santillana en un retrat cèlebre-, i encara que tampoc les preocupacions de qui s'hi aplica siguin del tot equiparables -per exemple, difícilment avui algú instruiria en la disposició espiritual d'un novici dient-li que evités ficar-se els dits al nas, com sant Vicent Ferrer al seu Tractat de la vida espiritual (Robles-Girbés-Sarrió 1998:80)-, em sembla que tots estaríem d'acord a admetre, en el temps de Martorell i en el nostre, que a les experiències de caire espiritual els convenen les condicions prèvies de retir i recolliment, i així, concedir un paper fonamental al silenci, sense el qual el contacte amb Déu, la seva contemplació, o el seu simple record, o la més elemental meditació, o rés, semblen difícils si no impossibles de realitzar-se.

Doncs bé, a ningú no escapa que el Tirant és la novel la del soroll. A les corts -i amb raó de més a Bizanci on existia el càrrec de silenciari o curador del silenci (Corbin 2016:82)-, amb festes, recepcions, banquets, músiques i danses; al camp de batalla amb l'entrexoc de les armes, el retruny dels cavalls al galop, el so de trompetes i timbals i la cridòria dels combatents; la remor dels combats $\mathrm{i}$ les atabalades navegacions a la Mediterrània; i per damunt de tot aquest parlar constant a tot arreu, a tothora $\mathrm{i}$ en tot to d'uns personatges amb uns altres, que fins $\mathrm{i}$ tot quan estan sols s'abandonen a sentits soliloquis, com si no poguessin suportar estar-se callats, fins al punt que Mario Vargas Llosa ha pogut escriure que els personatges són «cotorras ambulantes, surtidores humanos de palabras [que] con el menor pretexto dan rienda suelta a una elocuencia desbocada, todos padecen diarrea verbal» (1993: 594-596). La qual cosa ens hauria de fer entendre que si vida espiritual hi ha, aquesta pren una forma ben particular, que ens obliga, ja d'entrada, d'allunyar-la del recollit i silent endinsar-se en un mateix propi de la devotio moderna, per tal de «rumiar tot allò que provoqués el temor de Déu, o sigui: els pecats, la mort, el judici i l'infern» (Hauf 1990: 22). Al Tirant se'n parla, de tot això, és clar, però aquest parlar no es tradueix en vivència espiritual.

No res menys, el Tirant és obra d'un cavaller, orgullós del seu estament, com proclama des del principi de tot a la dedicatòria, on afirma que escriu «com ja yo sia per mon orde obligat manifestar los actes virtuosos dels cavallers passats», amb una finalitat primordial: per tal de treure'n «lo fruyt que s pertany, movent los coratges de aquells [en principi els «servidors»i amics («altres») de Ferrando de Portugal] e no duptar los aspres fets de les armes». El compromís amb el seu orde és tan profund que Martorell no esquiva els aspectes més candents que l'afecten en aquest moment de la història, entre els quals algunes discrepàncies amb l'Església no precisament irrellevants.

El punt de partença és, doncs, netament laic, i, venint d'un cavaller amb mentalitat feudal el realment estrany fóra de no ensopegar amb cap tret anticlerical -més precisament antimonàstic-, com de fet s'esdevé, per bé que embolcallat les més de les vegades amb una capa d'humor. El fa evident la comtessa de Vàroic expressant la temença que el seu marit «no 's pose en algun monestir» (c. 27); la reina de França alegrant-se de saber que el seu fill no havia mort ni havia entrat en un convent (c. 100); la princesa Ricomana assegurant que «no poria star una hora ab ell [Felip de França] gitada 
en un lit, ans deliberaria fer-me monja e star closa en un monestin», i, vorejant l'absurd, exclamant que «més stime ésser monja o muller de çabater que haver aquest per marit» (c. 110); i també es fa palès amb el to sorneguer de qui escriu que entre els pretendents de la infanta Ricomana constava el nebot del papa «que, volen dir alguns, seria fill» (c. 100).

Tot i el seu aspecte anecdòtic i insubstancial, no podem deixar de veure-hi una manifestació més del contrast entre la civilització medieval i la seva religió, el cristianisme, que en un llibre recent Michel Zink ha sintetitzat així: «La civilisation médiévale, féodale et chevaleresque, est une civilisation de l'honneur, qui redoute et abomine l'humiliation plus que tout. Mais sa religion, le christianisme, est une religion de l'humilité, dont la scène fondatrice, celle de la Passion du Christ et de sa mise en croix, est une scène d'humiliation» (2017:10). La humiliació, per contra, és el nucli de la doctrina franciscana - per citar un orde tractat amb alguna simpatia- fins al punt de descobrir-hi, com podem llegir als Fioretti per boca del mateix sant Francesc, la «perfetta letizia» (Davico Bonino1998:24-26).

Ara, no podem oblidar que, en un moviment de retorn, i per efecte d'una contaminació ambiental i literària, el mateix sant Francesc s'imaginava com aquell qui, talment un cavaller, anava a la quête de «Domina Paupertate», i que els mateixos Fioretti, recullen la reacció del cardenal Ugolino dei Segni, el futur papa Gregori IX, el qual en veure la multitud de seguidors del sant que ocupaven el prat de santa Maria degli Angeli, va exclamar: «Veramente questo sí è il campo e lo esercito de’ cavalieri de Dio!» (Davico Bonino 1998:48).

Així, no té res de sorprenent que algú proper a la sensibilitat franciscana com Peire Joan Olieu redacti un breu tractat com Lo cavalier armat, en el qual dóna a les armes un abast que coincideix força amb l'ideal franciscà en el sentit que, per exemple, el gonió significa «fe sobreauta e mesprezament de si meteys, e mespresament de tota gloria vana et ergulhosa» (Manselli 1976:208). I tampoc no té res de sorprenent que un home de frontera, i també acostat a la sensibilitat franciscana, com Ramon Llull compongui, per tal d'instruir el cavaller cristià un Libre de l'orde de cavalleria, menys espiritualista que el d'Olieu, que és justament el text que inspira l'ensenyament que sobre la matèria rep Tirant a l’inici de la novel la, entre el c. 32 i el 39, i que ja havia aparegut al Guillem de Vàroic.

Tanmateix, cal parar atenció al fet, no suficientment remarcat, que el Martorell del Tirant no és el del Guillem de Vàroic, i que la relació amb el text lul lià ve ara determinada per la nova història. Llull havia descrit un cavaller tan imbuit de valors clericals en la seva funció de mantenidor de l'ordre social i de defensa de l'Església, que podia afirmar, amb notable idealisme, que «los pus dos acostats officis que sien en est món, és offici de clergue e offici de cavaller» (Soler 1988:174). No hi ha dubte que aquesta proximitat a Martorell li feia una certa nosa. Quan Martorell exposa un aspecte tan sensible com és la significació de les armes oblida en llarga mesura el Libre de l'orde de cavalleria. En part, perquè l'armament ha canviat: l'elm, per exemple, ha substituït el capell de ferro, i el sentit de la peça que protegia el cap també canvia: d'alertar contra el deshonor passa a recordar que el cavaller ha de protegir el poble contra tota mena d'abusos, inclosos els reials. En part, perquè no té en compte certes armes, com la gorgera, que «environa el coyl del cavayler a significança de 
obediència a son senyor e a l'orde de cavayleria», o el que és el mateix, segons la fórmula d'André Vauchez: «la forme chrétienne de la condition militaire» (1994:63). En part, també, perquè en el cerimonial de l'adobament alguns elements han guanyat un pes decisiu, com els esperons, que, com l'espasa o el cavall, són interpretats per Martorell de manera diferent. No sembla casual que mentre per a Llull els esperons són el símbol de la diligència amb què el cavaller ha de dur a terme la seva missió, per a Martorell signifiquin que «lo cavaller deu punxar lo poble per fer-lo virtuós ... e deu punxar lo mal poble en fer-lo temerós» (c. 35). O que mentre per a Llull el cavall «és donat a cavaller per significança de nobilitat de coratge», i per Olieu «lo caval es Ihesu Crist e la sancta vida sua» (Manselli 1976:211), per a Martorell el cavall «significa lo poble», al qual ha de regir i tractar, si convé, amb «cor dur e fort...car si lo cavaller ha pietat ni merçé al qui merex mort, trobant-se administrador de justícia, dampna la sua ànima» (c. 35). No crec que hi hagi dubte en tot plegat: més que una vocació de servei governada per una ètica cristiana el que hi ha és una voluntat social de domini, essencialment laica.

En aquest sentit, no deixa de ser significatiu que Martorell al Guillem de Vàroic ometi tant el nom de l'autor com el del llibre d'on treu allò que exposa, mentre al Tirant remet a un títol concret, l'Arbre de batalles, un títol plausiblement lul lià, obra de l'eclesiàstic provençal Honoré Bouvet, que no conté res de tot això. L'Arbre de batalles és un text que va tenir un cert recorregut a l'Anglaterra que va conèixer Martorell, i que va interessar alguns escriptors castellans com el marquès de Santillana o mosén Diego de Valera, segons sembla a través de la Corona d'Aragó, on va deixar la seva empremta en l'Arbre d'honor de Gabriel Turell. Però aquest llibre només secundàriament és un text catequètic. Si pot interessar a un cavaller és perquè planteja i dóna solucions a assumptes que afecten les lleis de la guerra, $i$ sens dubte perquè, tot $i$ insistir en la superior necessitat dels valors morals, no condemna mai els actes cavallerescos. No per adhesió, sinó per un desenganyat i fatal pessimisme. A la pregunta de «se c'est chose possible et naturele que cestuy monde soit en paix [i] sans batailles, je respons vrayement que non». I per un motiu demolidor, que desenvolupa en inaugurar el seu tractat: perquè la primera batalla de la història no va tenir lloc a la terra, sinó al cel, amb la rebel lió de Lucífer, com, per cert, es recorda al Tirant al c. 81. (sobre la qüestió Espadaler 2016).

Si a Martorell li interessen preferentment obres d'aquesta mena és perquè s'avenen més amb la seva concepció de la cavalleria, i li permeten d'esquivar els compromisos a què l'obligaria la dimensió espiritual de la pràctica del seu ofici, i d'esborrar tot sentiment de pietat. Es comprèn millor aleshores el fet de recrear-se en aquelles parenceries que enervaven el Joan Rois de Corella del Triümfo de les dones, i que podem concretar en els estatuts de l'orde de la Garrotera, i especificar en l'exhibició satisfeta de la crueltat, i en el seu elogi. La frase deixa poc marge: «Tots los cavallers que bé volen usar e seguir les armes e lo stil de aquelles per haver renom e fama, han ésser cruels e tenir cadira enmig de infern» (c. 60). Per la qual cosa, la frase, d'un inconfusible regust corellià, inclosa a la Dedicatòria, segons la qual el Tirant, «a la cavalleria moral donarà lum e representarà los scenacles de bons costums, abolint la textura dels vicis e la ferocitat dels monstruossos actes», cal posar-la en quarantena.

SCRIPTA, Revista internacional de literatura i cultura medieval i moderna, núm. 14/ desembre 2019/ pp. 261 - 275 ISSN: 2340-4841 ·doi:10.7203/SCRIPTA.14.16369 
Podríem pensar que el Tirant disposat a tenir cadira enmig d'infern acaba de situar-nos en el punt més oposat al pensament eclesiàstic sobre els fets d'armes. Tanmateix, qui recorda que una de les condicions que van determinar històricament l'elecció de cavallers fou «que fuesen crueles para non aver piedad de robar lo de los enemigos nin de ferir nin de matan» (Viña Liste 1995:22), i ni ho desmenteix ni ho atenua, és un eclesiàstic: el bisbe Alonso de Cartagena, que dedica el seu Doctrinal de cavalleros, escrit el 1445, a un contemporani de Martorell, el comte de Dénia, Diego Gómez de Sandoval, personatge molt proper a l'autor del Tirant, segons Agustín Rubio Vela (2010).

Però és que, en el segle de Joana d'Arc, tampoc totes les dones eren tan «mansuetes» com les retrata Corella, començant per les «dones d'honon» relacionades amb els membres de la Garrotera (c. 93) o la «valent cavalleressa» Carmesina (c. 157). Una gran dona, feminista a consciència, culta com poques al seu temps, com Christine de Pizan, fusionant Vegeci, Honoré Bouvet i el seu personal criteri (Buschinger 2016), va compondre el 1410, a petició del duc de Borgonya Joan Sense Por, per a la instrucció del dofí Lluís de Guyenne, un important i exitós Livre des faits d'armes et de chevalerie.

El receptor de la ultrada frase de Tirant és el senyor de Muntalt, a qui el nostre heroi mata clavantli una daga a l'ull, perquè ell, que havia estat adobat pel comte de Vàroic, acceptava la mort pel compromís adquirit en ser fet cavaller: «més stime bé morir que mal viure». No cal dir que la resolució és lloada per Martorell, que el considera «màrtir d'armes», com a tots els que trobarien la mort - «sens que no 's volien desdir»- en les festes angleses - els que es desdeien eren «posats en gran desonor e infàmia». El rellevant aquí és que aquesta mena de màrtirs no només no són reconeguts per l'Església, com és obvi, sinó que de forma expressa no poden ser enterrats en terreny sagrat, almenys des del Concili Laterà del 1215. És el que va passar al Passo Honroso amb Asbert de Claramunt, com Martorell sabia molt bé, car, com anota el relator del Passo, Pero Rodríguez de Lena, «la sancta Yglesia no tiene por hijos a los que mueren en tales exercicios, porque non se pueden fazer sin peccado mortal» (1970:169). Si la realitat és aquesta no ha de passar per l'alt l'extrema gosadia de Martorell -la provocació, si es vol-, quan en proclamar la victòria de Tirant sobre el senyor de les Viles-Ermes, nou màrtir d'armes, els jutges del camp sentencien: «E per quant no pot ni deu ésser admès ha ecclesiàstica sepultura sens spressa licència de nosaltres, per què declaram, puix n'és mereixedor, que sia soterrat e admès als suffragis de sancta mare Sglésia» (c. 68). Contra tot pronòstic, Martorell ho ha capgirat completament, i en una nova demostració de la primacia laica, torna a posar els designis de la seva concepció de la cavalleria per damunt dels més severs interdictes eclesiàstics.

Això no obsta perquè els combats siguin precedits per manifestacions de la més sentida religiositat. Les donzelles preguen pels seus cavallers; aquests confessen i combreguen amb fervor, tot i que «ab un boçí de pa, car no ls darien en aquell cars lo cors de Jhesucrist»; tots van a missa -seca, baixa o solemne-, alguns es perdonen fraternalment la mort futura si s'ha d'escaure, i Tirant, que com a cavaller modèlic no pot oblidar que cal tenir Déu al seu costat, ja que en darrer terme és qui decideix el resultat de les batalles, s'obliga a respectar escrupolosament els procediments «per 
guanyar a nostre Senyor de sa part», i ofereix a Tomàs de Muntalbà el perdó mutu, amb la garantia d'emprendre el peregrinatge «a peu, descalç, a la sancta casa de Hierusalem, e star-hi un any e un dia e fer dir cascun dia XXX misses per les ànimes dels reys e dels duchs que yo de mes mans he morts» (c. 81). Finida victoriosament la batalla, i atribuït el bon resultat a Déu «qui és coneixedor de veritats e vençedor de les batailles» el qual «ha vista la mia ignosçència» (c. 82), només resta que Tirant elevi una oració d'agraïment (c. 83), que ve a ser una variant prou creativa de l'anomenada oració del gran perill dels textos èpics, i que amb més propietat, per bé que molt reduïdament, recita Hipòlit al c. 234.

En els episodis anglesos el que descobrim arreu és el tipus d'experiència religiosa que disgustava a Erasme, i que condemnava per superficial i supersticiosa, i que es vincula, de vegades grinyolant fortament, amb allò que un Corella trobava que formava part d'aquelles «cerimònies superbes» amb les quals els participants barataven «paradís per infern» (Carbonell 1973:77). Cert és que els personatges tenen força sovint presents la «inmaculada Verge, mare sua»,»el benaventurat senyor sanct Jordi» i altres sants, i Déu mateix, pel qual es jura en manta ocasió al llarg de la novel la (c. 102, 157 163, 220, 224, 226, 236, 238, 266, 388, 420...) -cosa que un rigorista com Ramon Llull condemnava sense pal liatius a la Medecina de pecat (Fernàndez, en premsa)-, i que hom s'autodefineix com a defensor de l'Església i de la «sancta fe cathòlica» a la menor oportunitat, i es presenta com a pecador i aspira a la plenitud de la vida eterna. Però pesa més en la mateixa religiositat el caràcter altament laic de qui, com Tirant, amb Martorell ufanós darrere, tesauritza en la seva capella les proves -escuts, senyeres, armes, camises- de les seves victòries, i de la seva pietat com a redemptor de captius (c. 108), per tal de fer visible la seva «mundana glòria» (c. 80). (Veg. sobre aquests episodis Espadaler 1997).

Aquesta tensió entre laïcitat extrema i dimensió religiosa de l'ofici de cavaller s'anul la quan Tirant es converteix en croat, contra el turc primer, i contra el magribí després, contra l’islam sempre, a partir de la constatació que, com es diu al c. 234 , «en la spasa és lo senyal de la creu». I partint també del principi que qui ara podrà ser considerat sense reserves màrtir tindrà garantit el paradís, car «tots los qui moren per aumentar la santa fe cathòlica van dret en la glòria de paradís» (c. 340). Mentre qui simplement hi participi, tindrà la salvació a tocar, car li seran perdonats els pecats «a pena e a culpa» (c. 291), que és, segons la Doctrina compendiosa, la manera popular d'anomenar «les planàries indulgències e remissions» (Martí de Barcelona 1929:74), que són també el perdó als croats, sense que, però, enlloc es vegi aquella purificació espiritual tota interior que havia previst sant Bernat en la Lloança de la nova milícia.

La croada -sense que hi hagi cerimònia de prendre la creu, ni es qualifiqui mai així l'acció religiosa i militar de Tirant- significa en realitat que allò que es conquereix amb l'espasa comporta la difusió de la fe. I viceversa: allò que obté la predicació de la fe i la conversió dels infidels consolida allò que s'havia aconseguit o s'havia d'aconseguir amb l'espasa. A risc d'anacronisme fóra instructiu de contrastar aquest plantejament amb l'Enchiridion erasmià (1991:46; Bataillon 1983:68). De fet 
es multipliquen els moments en què un Déu auxiliar dels cristians intervindrà al seu favor en les batalles, al cap i a la fi Ell és «vencedor de batalles». He tractat en altre lloc la relació del Tirant amb les coses de Grècia i Turquia i em permeto de remetre a aquests treballs per no tenir prolixitat (Espadaler 2011 a, 2011b). Només recordo que Martorell ignora completament el cristianisme ortodox i pinta un Bizanci que lluita per mantenir la «sancta fe cathòlica»-quan des de l'òptica catòlica estricta els grecs eren considerats herètics-, i que només una sola vegada sembla haver-hi una breu al lusió al problema cabdal de la unió de les Esglésies, si és que Tirant s'hi refereix quan expressa el desig de «socórrer l'emperial stat e la crestiana unió» (c. 400). Quant als turcs, caracteritzats amb cultemes magribins, como va posar de relleu Maria Jesús Rubiera (1993), els coneixements de Martorell no eren superiors als d'un europeu mig del seu temps, que eren escassos. Manifesta, però, curiosament a través de l'únic bizantí pro-turc de l'obra, el duc de Macedònia, tractat d'idòlatre per Carmesina (c. 124), allò mateix que va denunciar Eneas Silvio Piccolomini a propòsit del diàleg amb l'islam: «quant los fall rahó per aprovar lo seu mal, ab gran error defenen aquella ab la spasa en la mà» (c. 153).

Si en la lluita contra els turcs la qüestió religiosa és una dada més, un motiu més de confrontació amb qui és contemplat com l'alteritat absoluta, la religió, en canvi, aflora des del primer moment i es constitueix en matèria narrativa no pas menor perquè afecta directament el protagonista, en clau sentimental i en clau político-militar, en els episodis africans, que han estat considerats per la crítica recent sota el prisma de la croada, i en els quals és determinant la perspectiva portuguesa (Espadaler 2008:38-41; Beltran 2013:375). I com en una natural perllongació, és justament a Barberia que l'afer de Bizanci rep específicament la consideració de croada en el sermó que fa el mercedari Joan Ferrer, el qual insta als moros que són prests a convertir-se a fer el «sant viatge de Contestinoble»en el qual «si en batalles que contra lo Turch o lo soldà haureu moríeu, paraís no us pot mancar» (c. 403).

Des del punt de vista que ens ocupa el més rellevant és que qui es fa responsable de la cristianització dels territoris conquerits és el mateix Tirant. Ara, Tirant és un cavaller, i com és lògic té una formació religiosa limitada, com ell mateix reconeix. «Senyor -confessa al rei Escariano just abans que aquest rebi el bateig-, yo no y sé molt, però yo us diré lo que n'é après en lo temps de ma puerícia», que es resumeix en «tot lo que hun crestianíssim e devot cavaller y pot entendre» (c. 327). Es fa difícil de saber què és allò que un cristianíssim cavaller hi pot entendre, més que més quan hom observa que Martorell evita les concrecions al legant que la «sancta ley crestiana no vol ni consent que los cathòlics crestians hagen a creure ab rahons ni ab proves, sinó per sola fe». Així i tot, és digne de remarca que el rei Escariano resti admirat davant els coneixements de Tirant sobre la Trinitat, que és el punt més conflictiu en el debat teològic amb l'islam, com pot apreciar-se en la Tubfa d'Anselm Turmeda.

En l'activitat evangelitzadora duta a terme per cavallers, com a Le Canarien, observem que Jean de Bethencourt per tal d'adoctrinar el rei «payan» de Lanzarote, també abans de rebre el bateig, li explica en 6 capítols des de la creació del món al significat de la missa (Pico-Aznar-Corbella 
2003:271-288), explanació més ambiciosa que la de Tirant. Com també ho és la que es troba a la Crónica do descobrimento e conquista da Guiné de Gomes Eanes de Azurara, on hom ensenya «a oraçao do Pater noster, e Ave Maria, e os artigos da fé, e preceitos da lei, e obras de misericordia, e assim outras muitas cousas» (Reis Brasil 1989:166-167). És probable que la formació religiosa de Tirant no es trobi gaire lluny d'allò que disposava a finals del segle XIV el doctrinal conegut com Espill de consciència que afirmava que el cristià no clergue «deu creure distinctament e clara lo article primer, ço és, un Déu tot poderós, qui és un en essència e en Trinitat de persones, ço és, pare e fil e sant Sperit. Item deu creure los articles de la santa incarnació e nativitat e passió e ls altres de la humanitat de nostre senyor Jhesucrist, dels quals la Església fa solemnitat» (Casanova 1981:27).

Sigui com sigui, Tirant satisfà de tal manera les expectatives del rei Escariano, que aquest, en una nota anticlerical més, li assegura que «més notícia me has donada de la fe crestiana tu sol que no feren aquells frares que en ma companyia staven». S'explica així que triomfi fins al punt que amb l'ajut del frare mercedari valencià bategi «quaranta-e-quatre mília e cccxxvii moros e mores, que foren en camí de salvació» (c. 330). No podem obviar que es tracta d'aquelles xifres que s'allunyen «manifiestamente de las cifras equilibradas, pacíficas, serias y redondas» que tant plaïen a Rabelais, com ha explicat Mikail Bakhtin (1974:420), i que, en conseqüència, cal prendre com un gir autoirònic. I tampoc no podem deixar de banda com arriben el rei i tots aquests súbdits seus a la conversió. El rei Escariano es bateja seguint l'estela de la seva esposa, la reina de Tremicén, que abans s'havia enamorat a primera vista de Tirant, i això l'havia portada a interessar-se pel cristianisme, per tal d'eliminar obstacles entre ells (cc. 322 i 323). I Tirant, que no deixa res per verd, aprofita la circumstància, veient «ab los ulls de la pensa, camí per hon la sancta cristiandat poria ésser exalçada. Deliberà de mostrar molta amor a la reyna per què tingués voluntat de fer-se cristiana» (c. 324).

No crec que sigui gaire freqüent l'ús de la seducció al servei de «la sancta e verdadera ley cristiana» (c. 325). Però si, d'una banda, els resultats de determinis tan singulars li valen a Tirant ser assenyalat com «lo capità de la fe cristiana» (c. 337), «cap de la secular potència, spasa e coltell defenedor de la sancta religió cristiana» (c. 327), «aumentador de la sancta ley cristiana» (c. 338), «loctinent de Déu» (c. 351), «pare dels cristians» (c. 372) o «gran capità de Déu» (c. 396), a més de sant i Messies (c. 147), tot a més enmig d'un clima de tolerància religiosa amb els «enemichs de la sancta ley crestiana» (c. 122), car «els qui restaven en lur secta... no ls era feta violència alguna ni empediment» (c. 384; també c. 395), de l'altra, ens situen en una atmosfera ja coneguda de trasllat d'elements religiosos al terreny de l'amor profà, quan no directament al terreny eròtic. I aquest és un dels trets més destacats de tota la novel la, i presenta diverses cares.

Pot donar peu, per exemple, a tota una exhibició de relativisme moral com en l'episodi de la dama de Rodes, governat per la idea que «nostre Senyor algunes veguades permet algun gran mal per major benefici» (c. 98), protagonitzat per la qui, amb estrepitosa sornegueria, es qualifica de «virtuosa», «galant», «sobre totes les dones d'honor... exalçada», la qual es deixa enlluernar amb una 
facilitat olímpica pels diners i les joies de l'escrivà d'una nau genovesa.

Pot donar lloc a arriscades declaracions d'amor glorificant fins a la deïficació els personatges, àdhuc amb independència de la religió que professin. Així, Diafebus demana a Carmesina, amb els «genolls en la dura terra e ab les mans pleguades», «devotament e humil com si fos una sancta de paradís», que li permeti besar Estefania (c. 138). La reina de Tremicén es decideix a adorar a Tirant, «que altre Déu ma ley no m mostre», anul lant la temença que «si com a Déu te adorava, nom de mala mora merexeria» (c. 324). També Carmesina: «tostemps t'é amat e contemplat en loch de un déu», diu a Tirant (c. 271). I Tirant a ella, «la qual yo contínuament adore e contemple e li fas special oració», que per cert recita (c. 276). No menys atrevit és Hipòlit, que exclama davant una engrescada emperadriu: «¿Què fall a vostra magestat sinó que portàs diadema de sancta, e per vós se cantés Te Deum laudamus, e totes les sglésies fessen festa de XII liçons per ço com deveu ésser nomenada per lo món deessa de la terra?» (c. 542).

Pot dur a solapar completament les coses divines. Confessa Carmesina a Hipòlit que la seva amor per Tirant era tan «strema» que «desconexia a pare e mare e, si dir me fa, quasi a Déu...e volia-li oferir la mia persona ensemps ab tot quant he, e l'ànima fóra stada de Déu com d'aquesta vida passàs e, si l'agués volguda, també la y aguera dada» (c. 251). O a barrejar-les amb les humanes, amb un esperit paròdic relativament discret, com quan Diafebus besa Estefania «tres voltes en la boca a honor de la sancta Trinitat» (c. 146). O oferint una paròdia de major abast, com al c. 254, on Plaerdemavida narra a Carmesina què li passarà «com sereu morta e vendreu davant lo juhí de nostre Senyor» (c. 253), i que consisteix a fer un repàs que va des de la creació d'Eva i el manament de «crexeu e muntiplicau lo món e hompliu la terra», i a insistir en el fet que la seva salvació perilla perquè en rebutjar endur-se Tirant al llit l'àngel custodi informarà Déu que la princesa «no ha volgut servar los vostres sancts manaments».

I pot portar més concretament a aplicar expressions religioses a la vida eròtica, un hàbit que un savi admirador d'Erasme com Johan Huizinga veia com una manifestació «de verdadera irreligiosidad y libre burla» (1978:224). Però em sembla que caldria atenuar el dicteri del savi holandès, perquè, ben mirat, no hi ha tanta diferència entre els jocs de Martorell i els d'algú tan preocupat pels afers religiosos, corresponsal d'Erasme i de Luter, com Margarida de Navarra al seu Heptaméron, i encara falten alguns anys perquè Montaigne s'esveri davant conductes com la del rei Francesc I, germà de l'escriptora, capaces de combinar sense solució de continuïtat sexe i pietat (Essais, 1962 I, 56; Febvre 1996:40).

Hauf, d'altra banda, ha posat en relleu en els comentaris a la seva edició de 2004 que una gran majoria de les autoritats que Martorell cita són manipulacions tendencioses del vell i del nou testament que es van succeint des de la mateixa dedicatòria. La projecció al terreny eròtic sovinteja, i, per no allargar-me en paraules, ho redueixo a un parell de moments que il lustren prou bé aquesta constant desinhibició. Un al c. 233, quan Plaerdemavida, renya Tirant per la seva cauta timidesa davant Carmesina: «No sabeu vós com diu lo psalmista manus autem?». I afegeix, com a persona versada en 
aquests afers: «És la glossa: si adquerir voleu dona o donzella no vullau vergonya ni temor haver». L'altre, quan Plaedemavida accepta el matrimoni amb el senyor d'Agramunt, a precs de Tirant: «Presta és, senyor Tirant, la tua serventa: sia fet de mi segons la tua voluntat» (c. 382). Cosa que és, com comenta Hauf, «una atrevida utilització de les paraules a Maria de l’àngel Gabriel».

Si tot això és possible, és, com va escriure Huizinga, perquè «sólo una sociedad que está impregnada de religión y que considera la fe como algo natural conoce semejantes licencias» (1978:229). I justament per això es poden escriure coses com les que diu el senyor de la Pantanalea en veure Carmesina: «natura no podia més altament obrar que ha fet en la gran singularitat de la bellea que la majestat vostra posseheix, que per aquella vinch ara en notícia quanta és la glòria que los benaventurats sants senten en paradís en contemplar la divina essència, segons és scrit en la Sancta Scriptura que diu lo psalmiste, endreçant la sua rahó a Jhesucrist: «Senyor, aquell qui stà davant los teus hulls, mil anys són així com lo dia d’ayr, qui és passat» (c. 155). O sia una comparació, provinent dels Psalms «entre la bellesa de Carmesina i de la infinita essència de Déu!», com anota Hauf. O com Tirant, reunint en una mateixa frase el més terrenal i el més transcendent, en declarar a Carmesina: «us tinch per deessa de ma vida, la qual adore com a Déu, de qui spere haver salvació a la mia peccadora ànima» (c. 274). Salvació que als ulls de tothom té guanyada no pels seus amors, sinó per les seves victòries sobre turcs, berbers i genovesos. Acompanyada per la seguretat pètria de tenir Déu al seu costat, i que comunica sense parpellejar a l'emperador de Bizanci: «puix a Déu servesch en aument de la santa fe cathòlica, ell me darà la sua acostumada gràcia, que fins ací jamés me ha fallit» (c. 224).

I tot això es produeix enmig de manifestacions d'una religiositat autèntica, tot i que rutinària i externa, que dóna cabuda a debatre si «no ss podia dir missa ni consegrar lo preciós Cors de Jesucrist sens drap de lli» (c. 41), o si es pot consagrar després de migdia (c. 262), o a incloure prèdiques d'un frare sermonador «sobre les bones costumes que deuen aver los fills dels cavallers», assegurant al mateix temps que la «Sacra escriptura» confirma Ovidi quan «diu que lo major bé de aquest món és amor» (c. 221), sentència que no és convenient de llegir gaire de pressa. I aquests bones costumes són tres: «hoyr missa tots dies e dir alguna breu oració...saber bé legir e escriure...la tercera és que no sien juradors». Novament a risc d'anacronisme -molt lleu si partim de la data d'edició del Tirantcal reconèixer que el contrast entre aquestes tres costumes i les implacables 22 regles que conté l'Enchiridion o manual del cavaller cristià d'Erasme és altament revelador, i serveix per definir no només dues mentalitats, sinó per fer veure netament, i un cop més, que el Tirant no conté cap proposta renovadora, ni correctora, ni tan sols modèlica en un sentit exigent i cristià de la institució de la cavalleria.

Hom pot elevar una oració a la Mare de Déu, en perill de naufragar, en la qual s'afirma creure que «tu fuist verge ans del part, en lo part e aprés lo part» (c. 299), o cantar en plena sotsobra «la Salve regina» (c. 296), o fer una oració sentint-se a les portes de la mort evocant l'stabat mater (c. 291), o resar «una devota oració cascuna nit», com l'emperadriu (c. 261), tot i que la frase sigui una excusa 
per amagar el seu adulteri. Però la majoria de les vegades, per no dir sempre, la fe dels personatges es fa patent al servei d'interessos terrenals. Hom demana a Déu el triomf en les batalles, ja que Déu «és vençedor de batailles» (c 156), mentre, com diu el rei de Tunis, confirmant la creença des de l'altre costat, als «inferns és lo nostre Mafumet qui no ns ha pogut ajudar contra los cristians» (c. 345). I així i tot, no sempre se'l té present: «E si entra en fet d'armes -informa Diafebus de Tirant-, no invoca sanct negú sinó lo nom de Carmesina. E yo, moltes voltes lo y dich, per què no invoca, ab lo nom de Carmesina, algun altre sanct perquè li ajude en les batailles. Diu-me que per res no u faria, car aquell qui a molts serveix no serveix a negú» (c. 138). I hom organitza solemnes accions de gràcies per les victòries (cc. 285, 308, 409). Hom confia en els seus resos per a l'èxit en els diferents amors, pels quals, com la Viuda Reposada, pot fer un seguit d'«oracions, almoynes e dejunis» (c. 286), en una mostra més d'aquella religiositat formalista que disgustava a Erasme (Huizinga 1987:106). O pot endreçar una oració a «nostre senyor Déu Jhesucrist», com fa Carmesina, per sol licitar que el seu pare deixi posseir la «corona a mon senyor Tirant» (c. 278), per exemple. I pot, és clar, fer obres de pietat com la reina d'Etiòpia i fer edificar «molts monestirs e sglésies... i bons bisbats ab bona renda» (c. 409), o com el cavaller Espèrcius a la recent fundada vila de «Spertina la Venturosa» (c. 413). I quan hom s'enlaira, com Tirant responent a la pregunta formulada per Carmesina de «Què és fe?», no triga caure en el nivell més terra a terra, confonent la fe en Déu amb la fe en Tirant (c. 210).

Davant d'aquest panorama, qualsevol lector es convenç que la religió que es practica i s'explicita a la novel la no desmenteix les màximes que Tirant lo Blanc de Roca Salada llueix a la camisa regalada per Carmesina, on s'exhibeix una impactant mescla de sacre i profà, i que es posarà per combatre el turc, cenyida amb un cordó «tot d'or de sanct Francesch», i al cim «sanct Cristòfol, ab lo Jhesús a la part sinestra». I són aquestes: «Qui bé stà no s cuyta moure e, Qui seu en pla no ha d'on caure» (c. 132).

Però tothom sap que no tot el Tirant respon al mateix criteri ni a la mateixa sensibilitat. Que a partir d'un cert moment, que es fa particularment perceptible al voltant del c. 300 (en té 487), es comencen a produir canvis d'un gruix tal que no poden passar desapercebuts. L'humor, un dels atractius del Tirant, és exterminat. Els personatges comencen a ser designats sistemàticament amb qualificatius que cauen de ple en l'ordre moral, ja sense vestigis humorístics: «lo virtuós Tirant» (c.419), el «virtuós almirall» marquès de Liçana (c. 466) -un personatge desconegut, de cop sospitosament omnipresent-, «la virtuosa reina de Feç» (c. 431), «lo sanct arquebisbe» (c. 452). O jeràrquico-moral: «la ínclita reina» de Fes (c. 430), «la ínclita reyna de Ethiòpia» (c. 456), «la preclaríssima emperadriu» (c. 477), «l'excelsa senyora Carmesina» (c. 463), «l'il lustre e de preclara virtut Diafebus» (c. 442), «l'egregi duch de Macedònia» (c. 464). La parla dels personatges s'acompanya d'adjectius que ja no marquen tant la situació i la seva perspectiva o estat d’ànim, com les qualitats morals de qui parla tenint sempre en compte el seu estatus. I així ens trobem amb acotacions d'una grandiloqüència incontinent com aquesta de Carmesina adreçant-se al seu pare, amb qui tenia un tracte franc i gens sotmès al rigors del protocol: «respòs l'excelsa senyora ab graciosa, afable modesta continença e dix ab gran suavitat» (c. 452). O com aquesta, que voreja l'absurd: «dix -l'emperador, clar- ab 
gravitat real e humana entonació» (c. 440). De cop les accions, que abans pertanyien a l'argument, i no necessitaven ser justificades, comencen a ser-ho, amb la voluntat de tancar la història conferint un lloc honrós al seus personatges. El narrador s'adreça al lector a propòsit de les intencions d'aquestes accions. «E no us penseu...» (cc. 340, 477, 479), «E podeu contemplar...» (c. 463). Déu mateix és de sobte adjectivat - «la divina Magestat» (c. 439), «la divina Potència» (c.451)-, i dit més d'un cop «l'inmens Déu» (c. 414). Apareix un vocabulari nou, que no sempre és manejat amb encert, com ja va remarcar amb vehemència Joan Coromines (1974): «la intrínseca fortuna», «l'herètica pravitat»... L'erotisme, un dels principals condiments de la novel la, desapareix. Es reorienta la història de l'emperadriu i Hipòlit, esvaint el seu caràcter adúlter, al ludit eufemísticament com «l'amistat antiga», fent que Tirant l'institueixi com al seu hereu (c. 469), votat després per tots (c. 480), de manera que ell «fos elet emperador e marit de l'emperadriu»-es remarqui l'ordre-, i conduïts a l'altar oblidant ardors passades, fins al punt que són els amics de Tirant qui supliquen i demanen de gràcia a la «senyora excel lentíssima» de prendre el marit que «nosaltres vos darem» (c. 483). Carmesina i Estefania quan no poden veure els seus amics es tanquen en un convent, com la Güelfa, on desenvolupen, sobretot Carmesina, una inesperada disposició a la vida religiosa (c. 431), que confia a la nova i virtuosa reina de Fes, amb qui sempre havia parlat de molt distinta manera. Felip de França, que havia perdut totes les notes risibles al servei de la cristiandat, torna ser avar (c. 408). I per damunt de tot, convertida en reina, Plaerdemavida, una de les criatures més fresques i lliures de tota la literatura medieval, la gràcia de la qual residia en un enginy desimbolt i un llenguatge fresc i directe, al marge de qualsevol preocupació moral, es converteix en una preciosa ridícula que sermoneja citant Plató i fent teològiques al legacions de «molt santes autoritats».

I aquests canvis afecten de manera molt especial la religiositat en la novel la. Així hom se sorprèn que el narrador faci referència «al chantres de la capella de Tirant e de la capella del rey Scariano» (c. 459), quan fins al moment ni se n'havia insinuat l'existència. Al c. 340 llegim que «Tirant cascun dia feya dir missa». Això no és nou, al cap i a la fi era un costum que formava part de l'orde del seu camp (c. 145). Sí que ho és que afegeixi «e pregava al rey e als altres que la hoüssen de bon cor» -al c. 145 Tirant es preocupa només que als «senyors que hoyr-la volen» els sigui feta «molta de honor». I més nou encara és l'especificació, més endavant, que la missa fou «per ells devotament hoïda»(c. 425), en fort contrast amb el que passava al c. 65 , on els cavallers anaven a missa uns per acompanyar el rei, «los altres la reyna, los altres per veure les galants dames staven torbats»-expectativa que es repeteix al c. 134-, que pressuposa en els personatges una actitud radicalment distinta, fruit d'un teixit psicològic absolutament diferent.

La mort de Tirant, com ha estat observat (Guia 1996:149-171), segueix de prop les traces previstes en les arts de ben morir, i s'hi ajusta amb notable exactitud (Fàbrega 1955), en un clima de devoció i pietat, sense el més petit bri laïcitzant. S'esdevé, però, que al c. 234, quan encara érem lluny de la fi del llibre, Tirant, que s'acaba de trencar la cama fugint del llit de Carmesina, també es va sentir morir, però encarà la mort d'una manera molt diferent. Adreçant-se a Déu, «deya en forma de semblants paraules»: «O, senyor Déu eternal! Tu qui est ple de tota misericòrdia, fes-me gràcia que 
yo muyra en los braços de aquella virtuosíssima princessa (ironia poc innocent), per ço que la mia ànima en l'altre món haja millor repòs».

L'onada de pietat afecta també l'emperador, que resa al «Senyor inmens e incomprensible» (c. 447), al qual es dediquen un sèrie d'epítets, «rey dels reys e senyor dels senyorejants», establint un sistema que després seguirà Tirant davant «lo Corpus Domini»: «O redemptor de l'humanal linatge, Déu infinit sobre natura, pa de vida, tresor sens preu, joyel incomparable...» (c. 478), mai no vist fins aleshores. La pietat ara forma part de la vida d'uns personatges que s'encaminen a cloure el seu pas per la novel la, definint-se per damunt de tot com a cristians. I així, com el mateix Tirant, són capaços d'embolcallar de tons religiosos sense que soni cap nota discorde fets com l'alliberament de Diafebus anunciant uns nous set goigs (c. 464) «per a celebració d'una espècie de litúrgia laica familian», com apunta Hauf.

D'altra banda, les citacions es tornen exactes i si algun desajust hi ha, com detecta Hauf a propòsit de la Doctrina moral de Pacs, ja no es deu a una manipulació intencionada, sinó a una mala lectura o una distracció, mentre les cites en llatí, dels psalms, de sant Pau, dels Proverbis no es fan estranyes, com en el cas del mercedari Joan Ferrer (c. 403). I si Tirant mor com un perfecte cristià, el traspàs de Carmesina no és menys exemplar, no debades anota Hauf al c. 476 que «la devoció de Carmesina sobrepassa allò considerat normal», $\mathrm{i}$ inclou, entre les paraules de ben morir «les quals dix la princessa en la sua fi» (c. 478) una versió «pulcra i fidel del llatí» (Hauf) de l'ordo commendationis animae, i desenvolupa un «oracional força complet, amb textos ben representatius presentats en versions que gens no desmereixen de les sorgides de la ploma dels nostres autors religiosos». No sé si Martorell estava en disposició de fer una versió fidel i pulcra d'un text llatí.

Tot això són mutacions estilístiques, ideològiques i estètiques que no poden explicar-se per un simple canvi de model motivat pel superior pes de Rois de Corella a partir d'un cert moment. Ni per un canvi de criteri. Ni per una mena de palinòdia final per atenuar els excessos previs, com proposava Hauf (1993:111). Un artista no pot renunciar, sense incórrer en el risc costós, i en el fons inassumible de malbaratar la seva obra, a la naturalesa de les seves criatures, i menys encara de fer-les malbé, com en el cas de Plaerdemavida. Tantes i tan profundes alteracions només poden explicar-se per un canvi de mà. I ara és el moment de recordar que el colofó es tanca amb la següent frase que representa la voluntat de qui hi és reconegut com a responsable de la «quarta part, que és la fi del libre»: «E protesta -com protestava pels mateixos motius fra Pero Martines en prologar el Mirall de divinals assots (Riquer 1946:23), i com protestava, amb major coincidència de vocables, el valencià Francesc de Pertusa en el «Proemi» del Memorial de la fe catòlica (Sanchis Sivera 1999:226227)- que, si en lo dit libre haurà posades algunes coses que no sien cathòliques, que no les vol haver dites, ans les remet a correcció de la sancta cathòlica Sglésia». Joanot Martorell ni tenia aquesta preocupació, ni havia posat res que no li semblés perfectament catòlic, i tan segur n’estava, que fins i tot es permetia de corregir el parer de la santa catòlica Església. 


\section{Bibliografia}

Bajtin, Mijail (1974) La cultura popular en la Edad Media y en el Renacimiento, Barcelona.

Bataillon, Marcel (1983) Erasmo y el erasmismo, Barcelona.

Beltran, Vicenç (2013) «Don Ferrando, rei ‘spectant’. La connexió portuguesa del Tirant», Medioevo Roman₹o, 37, 2, 349-378.

Bouvet, Honoré (1493) Arbre de batailles, París.

Brasil, Reis (1989) Gomes Eanes de Azurara. Crónica do descobrimento e conquista da Guiné, Lisboa.

Buschinger, Danielle (2016) «La guerre dans la traduction haut-alémanique du Livre des faits d'armes et de chevalerie de Christine de Pizan», in Catalina Gîrbea (ed) Armes et jeux militaires dans l'imaginaire. XIIe-XVe siècles, París, 215-240.

Carbonell, Jordi (1973) Joan Roís de Corella. Obra profana, València.

Casanova, Emili (1981) Espill de consciència. Text doctrinal del segle XIV, Barcelona.

Corbin, Alain (2016) Histoire du silence, París.

Coromines, Joan (1974) Lleures i converses d'un filòleg, Barcelona.

Davico Bonino, Guido (1998) I fioretti di san Francesco, Torí.

Erasme de Rotterdam (1991) Manual del cavaller cristià, Barcelona. Clàssics del cristianisme.

Espadaler, Anton M. (1997) «Milícia i sexualitat a la part anglesa del Tirant», Anuari de Filologia, XX, $8,9-23$.

_. (2008) «Àfrica en el Curial e Güelfa i en el Tirant lo Blanch», Miscel •lània Gabriel Oliver Coll, Barcelona, 29-42.

- (2011a) «Notes sobre els dos orients del Tirant lo Blanch», La novel ta de Joanot Martorell $i$ l'Europa del segle XV, II, València, 673-692.

- - (2011b) «Les coses de Turquia en el Tirant lo Blanch», Joanot Martorell i la tardor de la cavalleria, València, 177-183.

- (2016) «Tot l'orde és en aquest libre scrit. Ramon Llull en el Tirant lo Blano, El procés, 8, 31-34.

Fàbrega, Àngel (1955) «Els primitius textos catalans de l'art de ben morin», Analecta Sacra Tarraconensia, 28, $79-104$.

Febvre, Lucien (1996) Amour sacré, amour profane, París.

Fernàndez, Anna (en premsa) Ramon Llull. Medecina de pecat.

Guia, Josep (1996) De Martorell a Corella. Descobrint l'autor del Tirant lo Blanc, Catarroja-Barcelona.

SCRIPTA, Revista internacional de literatura i cultura medieval i moderna, núm. 14/ desembre 2019/ pp. 261 - 275 
Hauf, Albert (1990) D'Eiximenis a sor Isabel de Villena, València/Barcelona. Institut Interuniversitari de Filologia Valenciana.

. (1993) «Tirant lo Blanch. Algunes qüestions que planteja la connexió corelliana», Actes del Novè

Col loqui Internacional de llengua i literatura catalanes, II, Barcelona, 69-116.

_. (2004) Joanot Martorell. Tirant lo Blanch, València.

Huizinga, Johan (1978) El otoño de la Edad Media, Madrid.

_. (1987) Erasmo, Barcelona.

Manselli, R (1976) «Lo cavalier armat», Cabiers de Fanjeaux, 11, 203-216.

Martí de Barcelona (1929) Francesc Eiximenis. Doctrina compendiosa, Barcelona, ENC.

Montaigne, Michel de (1962) Oeuvres complètes, París, Bibliothèque de la Pléiade.

Pico, Berta-Aznar, Eduardo- Corbella, Dolores (2003) Le Canarien, La Laguna, Instituto de Estudios Canarios.

Riquer, Martí de (1946) Fra Pero Martines. Mirall de divinals assots, Barcelona.

Robles,Adolfo -Girbés, Vicent J.- Sarrió, Ricard M. (1980) Vicent Ferrer. Tractat de la vida espiritual, Barcelona, Clàssics del cristianisme.

Rodríguez de Lena, Pero (1970) Libro del Passo Honroso, Madrid.

Rubiera, María Jesús (1993) Tirant contra el Islam. Altea.

Rubio Vela, Agustín (2010) Joanot Martorell y el condado de Dénia. Una clave en el Tirant, València.

Sanchis Sivera, Josep (1999) Estudis d'història cultural, València/Barcelona. Institut Interuniversitari de Filologia Valenciana.

Soler, Albert (1988) Ramon Llull. Llibre de l'orde de cavalleria, Barcelona, ENC.

Vargas Llosa, Mario (1993) «Tirant lo Blanc: las palabras como hechos», Actes del Symposion Tirant lo Blanc (Barcelona 19-23 novembre 1990), Barcelona, 587-603.

Vauchez, André (1994) La spiritualité du Moyen Âge occidental, París

Viña Liste, José María (1995) Alonso de Cartagena. Doctrinal de cavalleros, Universidade de Santiago de Compostela.

Zink, Michel (2017) L’bumiliation, le Moyen Âge et nous, París. 